\title{
On defining dietary fibre
}

\author{
Jonathan W. DeVries \\ Medallion Laboratories, Minneapolis, MN, USA
}

\begin{abstract}
Establishing a definition for dietary fibre has historically been a balance between nutrition knowledge and analytical method capabilities. While the most widely accepted physiologicallybased definitions have generally been accurate in defining the dietary fibre in foods, scientists and regulators have tended, in practice, to rely on analytical procedures as the definitional basis in fact. As a result, incongruities between theory and practice have resulted in confusion regarding the components that make up dietary fibre. In November 1998 the president of the American Association of Cereal Chemists (AACC) appointed an expert scientific review committee and charged it with the task of reviewing and, if necessary, updating the definition of dietary fibre. The committee was further charged with assessing the state of analytical methodology and making recommendations relevant to the updated definition. After due deliberation, an updated definition of dietary fibre was delivered to the AACC Board of Directors for consideration and adoption (Anon, 2000; Jones 2000b). The updated definition includes the same food components as the historical working definition used for approximately 30 years (a very important point, considering that the majority of the research of the past 30 years delineating the positive health effects of dietary fibre is based on that working definition). However, the updated definition more clearly delineates the make-up of dietary fibre and its physiological functionality. As a result, relatively few changes will be necessary in analytical methodology. Current methodologies, in particular AACC-approved method of analysis 32-05 (Grami, 2000), Association of Official Analytical Chemists' official method of analysis 985.29 (Horwitz, 2000a) or AACC 32-07 (Grami, 2000) Association of Official Analytical Chemists 991.43 (Horwitz, 2000a) will continue to be sufficient and used for most foods. A small number of additional methods will be necessary to quantify the dietary fibre levels in foods containing fibres such as fructans (polymers and oligomers of fructose, inulin), modified dextrins, and/or synthetic dietary fibre analogues.
\end{abstract}

Dietary fibre: Working definition of fibre: Methods for fibre analysis

From a philosophical point of view, nutrition scientists worldwide generally agree that a quality diet consists of eating plenty of high-fibre foods, including plenty of whole grains, fruits and vegetables. On the other hand, nutrition scientists also realize that a functional definition for dietary fibre is necessary for measuring a finite portion of a food or the food supply for research, regulation and labelling purposes. Such a definition must delineate that finite portion in a measurable, functional and effective way to ensure analytical accuracy in a nutritionally-meaningful fashion.

It is generally believed that Hipsley (1953) first applied the term 'dietary fibre' as a shorthand term for the nondigestible constituents that make up the plant cell wall in an attempt to distinguish some property or constituent of the food above and beyond what was then being measured by the crude fibre method(s). Between 1972 and 1976,
Burkitt et al. (1972), Trowell (1972a,b, 1974) and Painter (1975) adopted the term 'dietary fibre' in conjunction with a number of nutrition and health-related hypotheses that they were developing, subsequently referred to as their 'dietary fibre hypotheses'. 'Dietary fibre' was used to describe the remnants of plant components that were resistant to hydrolysis by human alimentary enzymes. Thus, it was a physiological-botanical description related to indigestibility in the human small intestine, with plant cell walls being the major source of digestion-resistant material. The components involved include cellulose, hemicellulose, lignin and associated minor substances such as waxes, cutin and suberin. The 'dietary fibre hypotheses' postulated the inverse relationship between dietary fibre consumption and the incidence of a number of 'Western' diseases (Table 1).

Abbreviation: AACC, American Association of Cereal Chemists 
Table 1. Diseases postulated to have an inverse relationship with dietary fibre intake

\begin{tabular}{lll}
\hline Constipation & Diverticular disease & Hiatus hernia \\
Appendicitis & Varicose veins & Piles (haemorrhoids) \\
Diabetes & Obesity & CHD \\
Cancer (large bowel) & Gallstones & \\
& &
\end{tabular}

Publication of the 'dietary fibre hypotheses' has resulted in numerous dietary fibre research projects in nutrition, analysis, food technology and other areas over the past three decades. This subsequent research has borne out the fibre-health relationship of many of, but not all, the aspects of the hypothesis.

In 1976 the dietary fibre definition related to the hypotheses was broadened (Trowell et al. 1976) to include all indigestible plant polysaccharides (the expansion being mainly the inclusion of plant storage saccharides), such as gums, modified celluloses, mucilages, oligosaccharides and pectins, resulting in a primarily physiological definition (based on edibility and resistance to digestion). This broadening of the definition was done on the basis of the chemical knowledge obtained between 1972 and 1976. The broadened 1976 definition includes cellulose, hemicellulose, lignin, gums, modified celluloses, mucilages, oligosaccharides and pectins, and associated minor substances such as waxes, cutin and suberin. The basis on which the additional nondigestible polysaccharides was included in the definition was that they were found to have the physiological actions that were attributed to dietary fibre, but could not necessarily be chemically identified as having their origins in the cell wall. The 1976 definition quickly gained widespread acceptance.

Theander \& Aman (1978, 1979, 1982), Asp \& Johanson (1981) and Asp et al. (1983) of Sweden, Van Soest \& McQueen (1973), Van Soest (1978), Baker et al. (1979), Furda et al. (1979), Baker (1981), Furda (1981) and Heckman \& Lane (1981) of the USA, Schweizer \& Wursch (1979) of Switzerland and Southgate $(1969,1977,1978)$ of the UK, amongst others, developed analytical procedures aimed at measuring the dietary fibre component of food to encourage consumers to increase dietary fibre intake. Removing the digestible portions of the food from the digestion-resistant portions using select enzymes was the researchers' primary tool. Success varied, and was in part limited by digestion activity present in commerciallyavailable enzymes that was not present in human enzymes.

\section{Practical application of a definition: from a hypothesis and definition to workable labelling regulations}

In order to convert a hypothesis and definition into labelling regulations that will benefit the consumer of high-fibre foods, appropriate analytical methodology was needed. The key to this link was an analytical method that matched the requirements of the definition and was applicable for widespread use in competent laboratories. Such method(s) served as the key to expanding nutrition research on dietary fibre and informing the consumer through nutrition labelling. The required method had to be accurate by simulating the human digestive
Table 2. Enzyme performance specifications required to accurately simulate human digestion for quantification of dietary fibre

\begin{tabular}{llc}
\hline Enzyme activity & Test substrate & Required recovery (\%) \\
\hline Pectinase & Pectin & $95-100$ \\
Hemicellulose & Larch gum & $95-100$ \\
Beta-glucanase & Barley gum & $95-100$ \\
Amylase & Maize starch & $0-2$ \\
Amylase & Wheat starch & $0-1$ \\
Protease & Casein & $0-2$ \\
\hline
\end{tabular}

behaviour designated in the definition, have realistic sample preparation steps, be rugged, be applicable in competent laboratories worldwide and be capable of being performed with acceptable precision. To accurately simulate human digestion the enzymes used in the method were required to meet relevant performance specifications (Table 2).

In the late 1970s Prosky \& Harland (1979) began to seek broad consensus on a dietary fibre definition in the scientific community. They also sought consensus on methodology commensurate with the definition to quantify dietary fibre in foods for nutrition improvement and labelling purposes by gathering the opinions of over 100 involved scientists worldwide. By the 1981 Spring Workshop of the Association of Official Analytical Chemists in Ottawa, Canada (Prosky, 1981) a general consensus was achieved on pursuing methodology that would quantify the fraction of food as defined earlier by Trowell et al. (1976). The methodological research works of Asp (Asp \& Johanson, 1981; Asp et al. 1983), Furda (1981) and Schweizer (Schweizer \& Wursch, 1979) were deemed to be the best approaches to achieving this quantification. In a cooperative effort led by Prosky, these researchers along with DeVries \& Harland, with the objective of quantifying the macronutrient in foods in line with the definition, arrived at a single method deemed suitable for a multinational collaborative study. Interest and support for this approach for quantifying the digestion-resistant portion of foods was so high that fortythree laboratories in twenty-nine countries immediately agreed to participate in the study. The method was adopted as the first official method of analysis for total dietary fibre (Prosky et al. 1984, 1985; Horwitz, 2000b), i.e. Association of Official Analytical Chemists' official method 985.29 (total dietary fibre in foods measured using an enzymicgravimetric method). Among the keys to success in achieving adequate methodology were specifications on enzyme purity and on the precise handling of the digestion steps of the method. Strict attention had to be paid to ensure the enzymes used were digesting the food components normally digested in the human system and not digesting the digestion-resistant components of the sample. This provision ensured both adequate performance of the method and accuracy in keeping with the dietary fibre definition.

Routine use of the method spread rapidly worldwide as the analytical and nutrition research communities continued to realise the positive effects of increased dietary fibre in the diet. As the important nutritional distinctions between insoluble and soluble dietary fibre emerged, Association of Official Analytical Chemists' official method 985.29 was modified to allow the isolation and quantification of the 
insoluble and soluble dietary fibre fractions as well as total dietary fibre.

With a generally-accepted 'gold standard' definition (Trowell et al. 1976), and a benchmark method (Association of Official Analytical Chemists' official method 985.29; Prosky et al. 1984, 1985; Horwitz, 2000b) in place, research scientists added improvements to the method or developed alternative approaches to arrive at the same quantification. While these methods utilized different approaches to quantify the digestion-resistant portion of the food sample, the benchmark for accuracy was the de facto defining method (Association of Official Analytical Chemists' official method 985.29). Consequently, all methods developed and adopted as official methods are based on the 'gold standard' definition, i.e. 'dietary fibre consists of the remnants of edible plant cells, polysaccharides, lignin and associated substances resistant to (hydrolysis) digestion by the alimentary enzymes of humans'. This 'gold standard' defines a macro constituent of foods that includes cellulose, hemicellulose, lignin, gums, modified celluloses, mucilages, oligosaccharides and pectins and associated minor substances such as waxes, cutin and suberin.

Since the acceptance of the Trowell et al. (1976) definition in 1981 and the subsequent development, validation and use of Association of Official Analytical Chemists' official method 985.29, the field of dietary fibre research underwent extensive change. With a standardized method in hand, scientists worldwide conducted physiological and nutrition research on the effects of dietary fibre in the diet. New fibre forms became available as a result of food scientist's efforts. As a result, questions began to arise regarding whether the definition of Trowell et al. (1976) was still the most relevant and whether the quantitative methodology for the determination of dietary fibre was comprehensive.

In November 1998, the president of the American Association of Cereal Chemists (AACC) appointed a scientific review committee and assigned that committee the task of reviewing and, if necessary, updating the definition of dietary fibre. Dr Dennis Gordon of North Dakota State University (Fargo, ND, USA) was appointed to chair the committee. The balance of the committee membership was from academia, government (and government retirees) and industry. A complete list of the committee members is provided in Table 3. After initial teleconference meetings, a decision was made to establish a website 'Defining Dietary Fibre' to provide ample opportunity for interested scientists worldwide to provide comments. The website was opened on 12 May 1999 and was available for approximately 9 months, during which time committee activities were broadcast and input was received. A wide variety of opinions were submitted to the committee from scientists from around the world. In many cases multiple participants carried out written Internet discussions.

The committee held three workshops, two of them as public forums. In June 1999, the AACC Dietary Fibre Definition Committee in cooperation with the Carbohydrate Technical Committee of the International Life Sciences Institute of North America held a workshop in Washington, DC. Key regulatory and health scientists from the (US) Food and Drink Administration, US Department of Agriculture, National Institutes for Health, Centers for Disease Control, academia and industry were invited. A preliminary definition for dietary fibre was presented for future consideration and feedback (DeVries \& Faubion, 1999). In July 1999, during the Institute of Food Technologists' meeting in Chicago, IL, USA the committee held a second dietary fibre definition workshop. The purpose of this workshop was to gather feedback from food, nutrition and analytical scientists on the preliminary definition resulting from the June workshop, further discuss the scientific basis for a definition and produce a refined definition, if necessary and if possible. Continual feedback from the website combined with committee teleconferences in August and September 1999 resulted in a version of the dietary fibre definition in the autumn of 1999 that was very similar to the final definition that was adopted. Results of the workshops were reported in a timely fashion in Cereal Foods World (DeVries et al. 1999; DeVries \& Faubion, 1999; Gordon, $1999 a, b, c$; Jones, 1999, 2000a,b,c) and on the website to ensure that all interested parties were provided with additional opportunity for comment. In the course of the committee's effort many ideas and suggestions were received from other interested parties. Most ideas and suggestions received were for specific aspects of a complete definitional statement. Few scientists offered a complete definition of dietary fibre, and far fewer included any substantiation. Suggestions offered were typically unaccompanied by an explanation, a rationale or relevant references.

At the AACC Annual International Meeting in Seattle, WA, USA in November 1999, a final workshop was held. The purpose of the workshop was to collect additional input regarding regulatory, analytical, nutritional and physiological aspects of dietary fibre in light of the previous year's effort. The committee concluded that the definition of dietary fibre was 'dietary fibre is the remnants of the edible part of plants and analogous carbohydrates that are resistant to digestion and absorption in the human small intestine with complete or partial fermentation in the human large intestine. It includes polysaccharides, oligosaccharides,

Table 3. Membership of the American Association of Cereal Chemists Expert Committee on dietary fibre

\begin{tabular}{llll}
\hline Academia & & Government & \\
Mary Ellen Camire & University of Maine & Betty Li & US Department of Agriculture \\
$\begin{array}{l}\text { Dennis Gordon } \\
\text { Julie Jones }\end{array}$ & North Dakota State University & David Lineback & JIFSAN, University of Maryland \\
$\begin{array}{l}\text { David Lineback } \\
\text { Ingredients - processors }\end{array}$ & JIFSAN, University of Maryland & Leon Prosky & US Food and Drug Administration, retired \\
$\begin{array}{l}\text { Stuart Craig } \\
\text { Bryan Tungland }\end{array}$ & Danisco Culter & Food manufacturers & \\
& Imperial Sensus & Sunsoo Cho & Kelloggs \\
Jonathan DeVries & General Mills \\
\hline
\end{tabular}


lignin and associated plant substances. Dietary fibre exhibits one or more of either laxation (faecal bulking and softening; increased frequency; and/or regularity), blood cholesterol attenuation, and/or blood glucose attenuation.'

Reading the definition shows it is obvious that the committee deemed it necessary: to clarify the constituent make-up of dietary fibre; to recognize that a primary characteristic of dietary fibre is resistance to digestion and absorption in the small intestine; to recognize that a primary characteristic of dietary fibre is fermentation in the large intestine; to include key physiological impacts demonstrated in the past 30 plus years of research.

Feedback received by the committee subsequent to the Seattle meeting indicated that the wording of the definition was a bit cumbersome, therefore the committee reconvened to reassess the exact phraseology. The result was the adoption in December 1999 of the final definition: 'dietary fibre is the edible parts of plants or analogous carbohydrates that are resistant to digestion and absorption in the human small intestine with complete or partial fermentation in the large intestine. Dietary fibre includes polysaccharides, oligosaccharides, lignin, and associated plant substances. Dietary fibres promote beneficial physiological effects including laxation, and/or blood cholesterol attenuation, and/or blood glucose attenuation'. This final definition was forwarded to the AACC Board of Directors in the spring of 2000 and adopted by the board on behalf of the association membership. The definition was published in Cereal Foods World (Jones, $2000 \mathrm{~b}$ ), and the notice of the adoption by the board of directors was published in Cereal Foods World (Anon, 2000). A final comprehensive report of the committee's activities was completed and delivered to the AACC Board of Directors in January 2001 for publication and distribution.

\section{Definition of dietary fibre}

'Dietary fibre is the edible parts of plants or analogous carbohydrates that are resistant to digestion and absorption in the human small intestine with complete or partial fermentation in the large intestine. Dietary fibre includes polysaccharides, oligosaccharides, lignin, and associated plant substances (Table 4). Dietary fibres promote beneficial physiological effects including laxation, and/or blood cholesterol attenuation, and/or blood glucose attenuation.'

'Dietary fibre ...'; the term to be defined. Since the term dietary fibre was coined by Hipsley (1953), the exact definition of the term has been controversial as scientists have studied various aspects of the food supply and impact of dietary fibre on health.

'... is the edible part ...' Obviously to be part of the diet, a component of food must be edible. Part indicates that dietary fibre makes up only a portion of the whole food or food product.

'... of plants ...' Dietary fibre has traditionally been considered to be of plant origin. Proposals have been put forward to consider the undigestible portions of animalbased foods as dietary fibre or, more explicitly, edible fibre (Trowell et al. 1978). However, the scientific community has not followed up on these proposals, and relevant research on non-plant sources of carbohydrates resistant to digestion has not been carried out.
Table 4. Constituents of dietary fibre according to American Association of Cereal Chemists' definition (Jones, 2000 b)

NSP and resistant oligosaccharides
Cellulose
Hemicellulose
Arabinoxylans
Arabinogalactans
Polyfructoses
Inulin
Oligofructans
Galacto-oligosaccharides
Gums
Mucilages
Pectins
Analogous carbohydrates
Indigestible dextrins
Resistant maltodextrins (from maize and other sources)
Resistant potato dextrins
Synthesized carbohydrate compounds
Polydextrose
Methyl cellulose
Hydroxypropylmethyl cellulose
Indigestible ('resistant') starches
Lignin substances associated with the NSP and lignin complex in
plants
Waxes
Phytate
Cutin
Saponins
Suberin
Tannins

'...or analogous carbohydrates ...' Carbohydrate(s) of structure(s) analogous to those of naturally-occurring dietary fibres have been shown to demonstrate the physiological properties of the respective materials to which they are analogous. These analogous carbohydrates are produced during food processing by chemical and/or physical processes affecting the digestibility of starches, or by purposeful synthesis.

'...that are resistant to digestion and absorption in the human small intestine ...' Resistance to digestion and absorption is the key to the unique position of dietary fibre in the human diet. To be bioavailable, nutrients other than dietary fibre must be broken down, solubilized, or otherwise modified, and absorbed through the walls of the small intestine. Dietary fibre is unique in that it must pass through the small intestine undigested to reach the large intestine, where it continues to impart its functionality.

'... with complete or partial fermentation in the large intestine ...' The positive health effects of dietary fibre are related, in part, to the fact that measurable fermentation of dietary fibre occurs in the large intestine. Fermentation has a positive impact on laxation, on colonic $\mathrm{pH}$, and produces by-products to which positive physiological effects have been ascribed.

'Dietary fibre includes polysaccharides ...' Polysaccharides such as cellulose and hemicellulose are the mainstay of dietary fibre. For many dietary fibres the large molecular size of the cellulose gives fibre its 'fibrous' appearance. For other dietary fibres the polysaccharides such as $\beta$-glucans 
provide the gummy gelatinous nature characteristic of soluble dietary fibres. All non-digestible fermentable polysaccharides, whether they are polyglucoses such as cellulose or $\beta$-glucans, polyfructoses such as inulin, heteropolymers such as arabinoxylans and arabinogalactans, or analogous carbohydrates, are included in the definition of dietary fibre.

'...oligosaccharides ...' Oligosaccharides, short-chain polysaccharides, which by convention are chains with an extent of polymerization between 3 and 10, exhibit some of the same physiological properties as their larger counterparts, and thus are included in this definition. Some fractions of oligosaccharides have been included methodologically, in practice, since the first formal definition of dietary fibre was proposed (Lee \& Prosky, 1994).

‘...lignin ...' Although not a polysaccharide per se, lignin is intricately tied to the dietary fibre polysaccharides in foods and increases the resistance to digestion.

'.... and associated plant substances.' Waxes, cutin and suberin are indigestible fatty acid derivatives, which, like lignin, are intricately tied to the dietary fibre polysaccharides, often serving as chemical cross-links between various other components and increasing resistance to digestion.

'Dietary fibres promote beneficial physiological effects ...' For a component of the diet to be considered important to nutrition and health, it must have either a negative or positive impact. In the case of dietary fibre the historical definitions have been used as the basis for the substantial body of scientific research that has shown the positive physiological benefits that are to be expected from dietary fibre. Analogous carbohydrates fitting the dietary fibre definition demonstrate at least one of the positive physiological effects included in this definition.

'...including laxation ...' Laxation is a very important physiological effect that results from increasing the dietary fibre component of the diet in place of other food components. It is a physiological effect that is almost taken for granted, and imparts positive feelings to the individual consuming the dietary fibre, along with other benefits of improved laxation.

'.... and/or ...' The use of 'and/or' is included in the definition of dietary fibre effects because not all dietary fibres impart all the positive physiological effects, but can be expected to impart at least one of them.

'...blood cholesterol attenuation and/or blood glucose attenuation.' 'To attenuate', in a scientific context, means to adjust a variable to a proper level (usually lower) or to adjust it to a desired level. When a signal or other variable is attenuated, it is adjusted so that it is neither too high nor too low. Research over the past several decades has shown that increased consumption of dietary fibres and high-fibre foods produces a positive adjustment in levels of serum cholesterol, a biomarker related to the risk of coronary disease. An increased consumption of dietary fibre and high-fibre foods in place of other foods in a particular meal also produces a measurable reduction in the peak level of serum glucose after eating, an effect generally deemed as beneficial to health, particularly in susceptible individuals. Although not all fibres and high-fibre foods in all studies have exhibited these beneficial properties (and thus, the inclusion of 'and/or' in the definition), the weight of evidence indicates these positive attributes for increased dietary fibre consumption are important and relevant.

The definition has three components: (1) a description of what dietary fibre is and why it is important. The description describes sources of fibre (traditional and analogous), edibility and behaviour in the body (resistant to digestion and absorption in the small intestine, fermentation in the large intestine); (2) a definition of the constituent makes up this unique part of the diet. Inclusion as a constituent is based on health and nutrition research and related chemical make-up and methodology. Constituents include resistant polysaccharides, resistant oligosaccharides, lignin and associated substances; (3) a listing of the defining (but not necessarily limiting) physiological effects of increased dietary fibre intake, supported by substantial scientific evidence at present. Physiological effects are a necessary part of the definition, without which there is no particular scientific, consumer, regulatory or producer interest. The physiological effects for which sufficient scientific evidence exists at present include laxation, blood cholesterol attenuation and blood glucose attenuation. Additional effects can be added later as scientific evidence becomes sufficient.

This definition reflects several very important concepts: (1) dietary fibre has been defined on the basis of the properties it exhibits that have been characterized as part of the extensive worldwide research effort of the past 30 years. This research effort has correlated the positive health effects of dietary fibre with its increased consumption. This definition makes reference to the plant components accepted as being present in the defined dietary fibre that imparted the positive health effects; (2) analogous dietary fibre is defined as those materials, not necessarily intrinsic to a part of a plant as consumed, exhibiting the digestion and fermentation properties of fibre. Analogous fibre, in addition to the requisite digestion and fermentation properties, must also exhibit a positive potential health benefit that has been ascribed to dietary fibre. This inclusion clearly acknowledges that certain food ingredients, whether they are plant extracts, concentrates, modified carbohydrates or compounds produced by design, exist and should be recognized as dietary fibre when considering their nutritional properties and labelling requirements when part of a food; (3) the definition, as written, clearly delineates the meaning of dietary fibre and analogous fibre, and defines the important and relevant functional properties of all dietary fibres.

The constituents of foods that will be included with this updated definition are not markedly different from those included with the definition put forward by researchers approximately 30 years ago. It is important to recognize this factor, because food composition has not changed substantially and, furthermore, the research demonstrating the positive health benefits has been based on working definitions used since the early 1970 s. The three physiological functions that have a substantial body of scientific evidence at present are included. Clarification is now provided on the need to modify methodology to fit the definition, rather than vice versa, and thus to include those highly-soluble soluble fibre components that previously have not been adequately quantified. Furthermore, clarification is provided that carbohydrates analogous in function to dietary fibre are included 
in dietary fibre, with the provision that these analogous carbohydrate(s) adequately demonstrate physiological functionality: (1) typically produced by acid or thermal treatments of starch hydrolysates, rendering the hydrolysate or portions thereof indigestible; (2) includes only those starches that are resistant to digestion in man and resistant to digestion in properly-designed analytical methods that include gelatinization steps to simulate cooking and processing.

\section{Conclusion}

The AACC definition fulfils the cyclic need for updating the definition of dietary fibre to be consistent with the current state of knowledge. The updated definition captures the current state of knowledge, while allowing for future updating as scientific knowledge unfolds. The definition maintains the essence of the definition of Trowell et al. (1976) that has provided a base for the past 30 years of research and the past 15-20 years of food package labelling. The definition is scientifically sound, based on years of nutrition research and physiological research, with input from expert scientists worldwide by means of scientific surveys and direct input through a dedicated website. The definition clarifies the salient points necessary for inclusion as dietary fibre, including those constituents that have always been present in the human diet, while allowing for scientifically-proven new ingredient forms to be included. The definition is aligned with future needs for updated methodology, labelling, nutrition research and health recommendations. The objective of all legitimate nutrition research is proper nutrition. Proper nutrition leads to improved health, which in turn allows for additional research to improve nutrition.

\section{References}

Anon (2000) AACC Board holds midyear meeting. Cereal Foods World 45, 325.

Asp N-G \& Johanson C-G (1981) Techniques for measuring dietary fiber. Principal aims of methods and a comparison of results obtained by different techniques. In Basic and Clinical Nutrition. vol. 3, The Analysis of Dietary Fiber in Food, pp. 173-190 [WPT James and O Theander, editors]. New York: Marcel Dekker.

Asp NG, Johansson C-G, Hallmer H \& Siljestrom M (1983) Rapid enzymatic assay of insoluble, and soluble dietary fiber. Journal of Agricultural and Food Chemistry 31, 476-482.

Baker D (1981) Notes on the neutral detergent fibre method. In The Analysis of Dietary Fiber in Food, pp. 159-162 [WPT James and O Theander, editors]. New York: Marcel Dekker.

Baker D, Norris KH \& Li BW (1979) Food fibre analysis: Advances in methodology. In Dietary Fibers: Chemistry and Nutrition, pp. 67-78 [GE Inglett and SI Falkehag, editors]. London: Academic Press.

Burkitt DP, Walker ARP \& Painter NS (1972) Effect of dietary fibre on stools and transit times, and its role in the causation of disease. Lancet ii, 1408-1412.

DeVries JW \& Faubion JM (1999) Defining dietary fiber: A report on the AACC/ILSINA Consensus Workshop. Cereal Foods World 44, 506-507.

DeVries JW, Prosky L, Li B \& Cho S (1999) A historical perspective on defining dietary fiber. Cereal Foods World 44, 367-369.
Furda I (1981) Simultaneous analysis of soluble and insoluble dietary fiber. In The Analysis of Fiber in Foods, pp. 163-172 [WPT James and O Theander, editors]. New York: Marcel Dekker.

Furda I, Gengler SC, Johnson RR, Magnuson JS \& Smith DE (1979) Proceedings of the 93rd Annual Meeting of the AOAC, Washington DC. Washington, DC: AOAC.

Gordon DT (1999a) Defining dietary fiber. Cereal Foods World 44, 74.

Gordon DT (1999b) Defining dietary fiber - a progress report. Cereal Foods World 44, 336.

Gordon DT (1999c) What is dietary fiber? Food Technology 53, 242.

Grami B (editor) (2000) Approved Methods of the American Association of Cereal Chemists, 10th ed. St Paul, MN: American Association of Cereal Chemists.

Heckman MM \& Lane SA (1981) Comparison of dietary fiber methods for food. Journal of the Association of Official Analytical Chemists 64, 1339-1343.

Hipsley EH (1953) Dietary 'fibre' and pregnancy toxaemia. British Medical Journal 2, 420-422.

Horwitz W (editor) (2000a) Official Methods of Analysis, 17th ed. Gaithersburg, MD: AOAC International.

Horwitz W (editor) (2000b) Official Methods of Analysis 985.29. Total Dietary Fibre in Foods-Enzymatic-Gravimetric Method. Gaithersburg, MD: AOAC International.

Jones JM (1999) Mixed news on fiber. Cereal Foods World 44, $484-485$.

Jones JM (2000a) Defining dietary fiber. International Food Ingredients 2, 11-13.

Jones JM (2000b) Update on defining dietary fiber. Cereal Foods World 45, 219-220.

Jones JM (2000c) New AACC dietary fiber definition sets the stage for annual meeting technical round tables. Cereal Foods World 45, 404.

Lee SC \& Prosky L (1994) Perspectives on a new dietary fiber definition. Cereal Foods World 39, 767-768.

Painter NS (1975) Diverticular Disease of the Colon: A Deficiency Disease of Western Civilization. London: Heinemann.

Prosky L (1981) Discussion on the Definition and Analysis of Fibre. Association of Official Analytical Chemists Spring Workshop, Ottawa, Ontario. Washington, DC: AOAC.

Prosky L, Asp N-G, Furda I, DeVries JW, Schweizer TF \& Harland BF (1984) Determination of total dietary fiber in foods and food products and total diets: interlaboratory study. Journal of the Association of Official Analytical Chemists 67, 1044-1053.

Prosky L, Asp N-G, Furda I, DeVries JW, Schweizer TF \& Harland BF (1985) Determination of total dietary fiber in foods and food products: collaborative study. Journal of the Association of Official Analytical Chemists 68, 677-679.

Prosky L \& Harland BF (1979) Need definition, and rationale regarding dietary fiber. Proceedings of the 93rd Annual Meeting of the Association of Official Analytical Chemists, Washington, $D C$. Washington, DC: AOAC.

Schweizer TF \& Wursch P (1979) Analysis of dietary fiber. Journal of the Science of Food and Agriculture 30, 613-619.

Southgate DAT (1969) Determination of carbohydrates in foods. II. Unavailable carbohydrates. Journal of the Science of Food and Agriculture 20, 331-335.

Southgate DAT (1977) The definition and analysis of dietary fibre. Nutrition Reviews 35, 31-37.

Southgate DAT (1978) Dietary fibre: analysis and food sources. American Journal of Clinical Nutrition 31, Suppl., S107-S110.

Theander O \& Aman P (1978) The chemistry morphology, and analysis of dietary fiber components. Abstracts of Papers American Chemical Society 176, CELL1. 
Theander O \& Aman P (1979) Studies on dietary fibres. I. Analysis and chemical characterization of water-soluble and waterinsoluble dietary fibres. Swedish Journal of Agricultural Research 9, 97-106.

Theander O \& Aman P (1982) Studies in dietary fiber. A method for the analysis and chemical characterization of total dietary fibre. Journal of the Science of Food and Agriculture 33, 340-344.

Trowell H (1972a) Crude fibre, dietary fibre and atherosclerosis. Atherosclerosis 16, 138.

Trowell H (1972b) Ischemic heart disease and dietary fibre. American Journal of Clinical Nutrition 25, 926-932.
Trowell HC (1974) Definition of dietary fibre. Lancet i, 503.

Trowell H, Godding E, Spiller G \& Briggs G (1978) Fibre bibliographies and terminology. American Journal of Clinical Nutrition 31, 1489-1490.

Trowell HC, Southgate DAT, Wolever TMS, Leeds AR, Gassull MA \& Jenkins DJA (1976) Dietary fiber redefined. Lancet i, 967.

Van Soest PJ (1978) Component analysis of fibre in foods. Summary and recommendations. American Journal of Clinical Nutrition 31, Suppl., S75-S76.

Van Soest PJ \& McQueen RW (1973) The chemistry and estimation of fibre. Proceedings of the Nutrition Society 32, 123-130. 